\title{
Gramaticalização do verbo danar como marcador aspectual: um legado latino
}

\section{Grammaticalization of the verb danar as an aspectual marker: a Latin legacy}

Sueli Maria Coelho

Universidade Federal de Minas Gerais (UFMG), Belo Horizonte / Brasil su.coelho@uol.com.br

Thaís Franco de Paula

Universidade Federal de Minas Gerais (UFMG), Belo Horizonte / Brasil thaisfrancodepaula@yahoo.com.br

Resumo: Apoiado teoricamente nos pressupostos da Linguística Cognitiva e da Gramática de Construções, este texto se propõe a discutir a hipótese de que a construção aspectual formada de $\mathrm{V} 1_{\text {danar }}+\left(\right.$ prep) $+\mathrm{V} 2_{\text {infinitivo }}$ tem raízes latinas, dado que construções sintáticas semelhantes já eram identificadas no século I da Era Cristã. Os resultados alcançados demonstraram que tal construção emergiu com a função aspectual no século XX, mas que ela resulta de um processo de mesclagem das duas construções latinas que a precederam historicamente, das quais herdou traços sintáticos e semânticos.

Palavras-chave: construção aspectual inceptiva; relação de herança; mesclagem conceitual.

Abstract: Based on the theoretical assumptions of Cognitive Linguistics and of Construction Grammar, this paper proposes to discuss the hypothesis that the aspectual construction formed by V1danar + (prep) + V2infinitive has Latin roots because similar syntactic constructions 
had been already identified in the first century of the Christian Era. The results achieved had shown that the aspectual construction emerged in the twentieth century, but it is the result of a merging process of the two Latin constructions that preceded it historically, which inherited syntactic and semantic features.

Keywords: inceptive aspectual construction; inheritance relationship; conceptual blending.

Recebido em: 4 de novembro de 2016.

Aprovado em: 18 de novembro de 2016.

\section{Considerações iniciais}

A dinamicidade é não só uma característica das línguas naturais, como também um dos princípios da mudança linguística, já que, ao longo do tempo, algumas formas podem desaparecer, emergir ou mesmo adquirir novas funções na língua. Tais processos atingem indistintamente todos os níveis linguísticos, embora alguns deles sejam mais sensíveis às incorporações e, portanto, mais passíveis de mudança, como é o caso do léxico ou do estrato fonológico, por exemplo. Além disso, o percurso de uma mudança linguística não é totalmente previsível, tampouco é possível determinar com precisão um intervalo de tempo máximo para a sua implementação. Assim, alguns processos de recategorização ou de reanálise linguística podem compreender uma cronologia tão extensa que, por vezes, seu percurso nem pode ser recuperado. Mesmo nos casos em que tal recuperação é viável, algumas formas, especialmente aquelas cuja história é bastante pregressa, podem passar despercebidas, não só ao falante, como também ao próprio linguista, dependendo, principalmente, do recorte temporal imposto ao corpus utilizado para compor a amostra de língua analisada. Em face dessa limitação, corremos o risco de categorizar algumas construções como formas emergentes, quando, na verdade, elas já estão na língua há bastante tempo, embora em estado de latência. Semelhante fato pode estar ocorrendo com o verbo danar empregado na função de marcador aspectual, em construções como as ilustradas de (1) a (4): 
(1) "Finda a exibição, João danou a falar de religião" (MEU..., 2007, grifos nossos);

(2) "Mas o Coritiba mostrou garra, danou a correr e encostou de vez, com Bill aos 29 e aos 41" (GRECO, 2011, grifos nossos);

(3) "Mãe danou de ficar triste, falando pelos cantos" (ESTEVES, [entre 2000 e 2008], grifos nossos);

(4) “Agora Abras danou pra falar mal do galo... lamentável” (grifos nossos). ${ }^{1}$

A despeito de as construções aspectuais formadas por $\mathrm{V} 1_{\text {danar }}$ $+($ prep $)+\mathrm{V} 2_{\text {infinitivo }}$ serem mais prototípicas da modalidade oral, especialmente em contextos menos formais, elas são bastante produtivas na língua, inclusive em alguns gêneros da modalidade escrita, conforme registrou Paula (2014), ao descrever o processo de gramaticalização desse verbo para marcação de aspecto inceptivo com prolongamento da ação no português brasileiro. Paula e Coelho (2015) demonstraram que essa recategorização do verbo danar como marcador de aspecto inceptivo com prolongamento da ação resulta de um processo metafórico que envolve os esquemas imagéticos movimento e força, os quais já se encontravam subjacentes em danar concreto. Essa persistência de traços lexicais explica, assim, a possibilidade de esse verbo, não prototípico lexicalmente para a marcação de aspecto, assumir tal função na língua, em construções nas quais se junta a uma preposição e a um V2 ${ }_{\text {infinitivo }}$.

Considerando-se que, segundo estudo de Coelho (2014), as construções formadas por $\mathrm{V} 1_{\text {danar }}+\left(\right.$ prep) $+\mathrm{V} 2_{\text {infinitivo }}$ concorrem com outras formalmente semelhantes encabeçadas, respectivamente, pelos verbos (a)garrar, desandar e desatar para expressar cumulativamente os aspectos incoativo, cursivo e iterativo, há de se pensar que tais construções são relativamente recentes na língua, concorrendo com construções aspectuais inceptivas prototípicas, como aquelas encabeçadas pelos verbos começar e principiar, por exemplo, tal como cogitou Travaglia (2010). Essa conjectura encontra respaldo no trabalho de Paula (2014), que, num estudo diacrônico em corpus compreendendo dados dos séculos XVIII ao XX, identificou as primeiras ocorrências da construção aspectual V1 $1_{\text {danar }}+$ (prep) $+\mathrm{V} 2_{\text {infinitivo }}$ apenas no séc. XX. Entretanto, uma busca mais meticulosa em estágios bem anteriores da língua revela que,

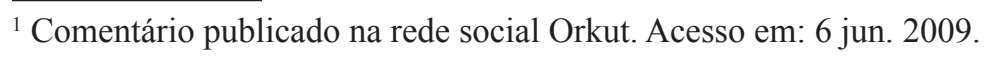


já no século I da Era Cristã, há registros do verbo danar figurando em contextos sintáticos semelhantes àqueles ilustrados de (1) a (4), conforme se demonstra em (5) e em (6):

(5) Damnare ad bestias (condenar às feras)

[Damna- - - a $\quad$ ad besti- -as]

[Condenar infinitivo presente preposição $a$ fera acusativo plural]

(6) Damnare vesci (condenar a alimentar/comer)

[Damna-

-re vesc-

-i]

[Condenar infinitivo presente alimentar infinitivo presente depoente]

As construções latinas glosadas acima são formadas, respectivamente, de $\mathrm{V} 1_{\text {danar }}+\operatorname{prep}_{\mathrm{a}}+\mathrm{Ne}$ de $\mathrm{V} 1_{\text {danar }}+\mathrm{V} 2_{\text {infinitivo }}$. A estrutura descrita em (6) revela um uso já gramatical do verbo danar, o que evoca a hipótese de que as construções em que o V1 $1_{\text {danar }}$ denota aspecto inceptivo com prolongamento de ação na língua portuguesa possam não ser, como se cogitou nos estudos anteriormente mencionados, construções emergentes na língua; há a possibilidade de serem, contrariamente, um legado da língua latina cujos contextos sintáticos que permitiram a gramaticalização de $\mathrm{V} 1_{\text {danar }}$ lexical em forma gramatical sejam aqueles supracitados. Constitui, pois, objetivo geral deste ensaio explorar essa conjectura, buscando evidências empíricas e teóricas que nos permitam julgar sua adequação, com vistas a contribuir para uma melhor descrição do aspecto verbal da língua portuguesa, especialmente no tocante à expressão cumulativa dessa categoria. Tal contribuição é relevante para os estudos linguísticos não só por ajudar a elucidar o processo de gramaticalização do verbo danar como marcador aspectual na língua, mas também porque, conforme observa Travaglia (1985, ${ }^{2}$ p. 21$)$, "no estudo do verbo no Português pouca atenção tem sido dada à categoria de aspecto". Nosso objetivo específico é delineado pelo quadro teórico da Linguística Cognitiva, mais estritamente relacionado à Gramática de Construções, e consiste em estabelecer a relação de herança por extensão metafórica

${ }^{2}$ Originalmente publicado em 1981. 
entre as construções do século I e a do século XX e, com base nessa relação, elucidar o fenômeno de herança de padrão sintático do processo de gramaticalização do verbo danar como marcador de aspecto inceptivo com prolongamento da ação na língua portuguesa. Para tentarmos alcançar tal propósito, adotaremos como ponto de partida a etimologia do verbo de que nos ocupamos, a qual será resenhada na segunda seção. $\mathrm{Na}$ terceira seção, buscaremos estabelecer a relação de herança entre as construções latinas e a construção aspectual do português contemporâneo, visando a julgar a adequação de nossa hipótese, passando, em seguida, às nossas considerações finais.

\section{In principio erat damnum: a etimologia de danar}

Uma incursão pelas searas da etimologia é um recurso metodológico não só desejável como também inevitável, quando se busca recompor a evolução de determinada forma linguística com vistas a entender seu percurso de mudança. Em se tratando especificamente do estudo de um processo de gramaticalização, tal recurso é bastante adequado, já que, desde as primeiras abordagens sobre o tema, há referência àquilo que entendemos ser o étimo de uma forma gramatical. Ao traçarem o percurso histórico dos estudos sobre a gramaticalização de formas linguísticas, Heine, Claudi e Hünnemeyer (1991) atribuem a estudiosos orientais o mérito por promoverem os primeiros esboços da gramaticalização, concebida como o processo segundo o qual, a partir de um continuum de abstração semântica, uma forma lexical se transforma em uma forma gramatical, ou como um processo pelo qual uma forma já gramatical intensifica seu grau de gramaticalidade na língua.

Harbsmeier (1979) acrescenta que Zhou Bo-qi, representante da dinastia Yuan (1271-1368), já defendia o postulado de que todos os símbolos vazios eram historicamente oriundos dos símbolos plenos. Heine, Claudi e Hünnemeyer (1991) registram que o interesse pela gramaticalização, tal como definida no parágrafo precedente, só surgiu no século XVIII, quando eruditos como os filósofos franceses Etienne Bonnot de Condillac e Jean Jacques Rousseau argumentaram que tanto a complexidade gramatical quanto a abstração vocabular são diacronicamente derivadas de lexemas concretos. A paternidade científica da investigação desse processo linguístico é atribuída a um contemporâneo de Condillac, J. Horne Tooke, para quem 'o 'segredo' 
das palavras encontra-se em sua etimologia" (HEINE; CLAUDI; HÜNNEMEYER, 1991, p. 5, tradução nossa). ${ }^{3}$ Sabe-se que, no percurso da língua, os semas etimológicos vão passando por um processo de abstração e, consequentemente, novos semas vão surgindo, o que implica uma diversidade de novos sentidos para uma mesma forma.

Objeto de ampla especulação entre os grandes pensadores clássicos, a distinção entre formas concretas e abstratas é tão antiga quanto controversa. Em face disso e de sua crucial importância para o estudo de processos de gramaticalização, especialmente para aqueles que, valendo-se de uma perspectiva diacrônica, buscam reconstituir o percurso da mudança linguística, Coelho (2006) propôs a adoção de um critério etimológico para precisar o grau de abstração de uma forma linguística. Segundo a autora, seu mérito reside em dois pontos principais: "(a) constitui uma forma de delimitação baseada em critérios científicos e não apenas intuitivos e (b) atende ao processo metafórico da abstração, que permite a difusão do processo" (COELHO, 2006, p. 115). Nessa concepção, consideram-se como acepções concretas apenas o(s) sentido(s) etimológico(s) da forma e, como acepções abstratas, todos os demais sentidos adquiridos ao longo do curso de sua história linguística.

Além dos méritos apontados por Coelho (2006), a proposta de adoção de um critério etimológico faz eco com o princípio da persistência, proposto por Hopper (1991) para identificar processos de gramaticalização. Esse princípio prevê a possibilidade de, a despeito da abstração semântica que viabiliza a gramaticalização, alguns traços semânticos da forma-fonte serem preservados na forma-alvo, gerando, em alguns casos, determinadas restrições sintáticas na construção. Assim, seguindo o conselho de Tooke (1857 apud HEINE; CLAUDI; HÜNNEMEYER, 1991) e também buscando identificar a persistência de algum traço semântico/sintático que nos permita estabelecer uma relação de herança entre as construções do século I e aquela do século XX, vamos tentar desvendar o "segredo" do verbo danar aspectual partindo, pois, de sua etimologia.

Diferentemente do que ocorre com alguns verbetes, que apresentam etimologia duvidosa, não há dissidência de informação entre os autores compulsados no que diz respeito ao verbo danar. Todos atribuem a etimologia desse verbo ao latim damnare, remetendo à palavra

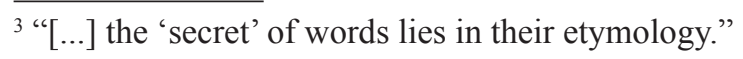


dano cuja etimologia é também latina: damnum (cf. NASCENTES, 1933; CUNHA, 1997; ${ }^{4}$ MACHADO, 1987). Assim, de acordo com informações extraídas de Cunha (1997, p. 239), que estima o século XIII como a data provável da primeira ocorrência do verbete danar na língua portuguesa, etimologicamente esse verbo significa "prejudicar, irritar, comunicar a hidrofobia, encolerizar." 5

Um ponto que evoca atenção no tocante ao conjunto dos sentidos apresentados pelos lexicógrafos consultados é que o argumento interno de todos os verbos arrolados como sinônimos de danar é paciente de uma ação sobre a qual não exerce controle algum, mas é por ela afetado. ${ }^{6}$ Trata-se, portanto, de um movimento causado por outro, ou seja, pela ação de uma "força" contra a qual o paciente nada pode. Esse traço semântico da falta de domínio do paciente sobre o estado em que se encontra parece estar metaforicamente preservado na estrutura argumental das construções aspectuais por nós analisadas, já que aquele que "dana a falar", por exemplo, o faz movido por falta de controle psicológico sobre a ação expressa por V2, prolongando-a por um intervalo de tempo superior ao esperado ou ao desejado pelo interlocutor. Tem-se, pois, nessa construção, uma extensão metafórica dos papéis semânticos presentes nos sentidos etimológicos do verbo danar, uma vez que a falta de controle do paciente da construção original se metaforiza na falta de controle psicológico experimentada pelo sujeito agente da ação expressa pelo V2 da construção aspectual.

Identificada a etimologia latina do verbo danar, podemos recompor o percurso fonético que o originou na língua portuguesa ainda no período ducentista. Trata-se, segundo nos ensina Coutinho (1969), de um processo de assimilação, ou seja, de um tipo de metaplasmo por permuta que consiste na "aproximação ou perfeita identidade de dois fonemas, resultante da influência que um exerce sobre o outro"

\footnotetext{
${ }^{4}$ Originalmente publicado em 1982.

${ }^{5}$ Machado (1987) não discorda quanto à origem latina do verbete, mas não inclui entre os sentidos etimológicos do verbo nem "prejudicar", nem "encolerizar" e acrescenta o sentido de "condenar": "condenar em justiça; declarar culpado; obrigar por estipulação a; condenar, censurar, criticar".

${ }^{6}$ Considerando-se a estrutura argumental do verbo danar, é esperado que seu complemento seja marcado pela afetação. Nossa observação é tão somente relativa à persistência de tal afetação no processo de gramaticalização da construção, conforme se demonstrará na seção destinada à análise.
} 
(COUTINHO, 1969, p. 143). Tal assimilação, de acordo com esse mestre da gramática histórica, é, no caso em análise, total - "quando se identifica o fonema assimilado com o assimilador" (COUTINHO, 1969, p. 144) - e regressiva, já que o fonema assimilador está em segundo lugar: damnare $>$ danar.

Solucionada a etimologia e reconstituída a forma fonética do verbo de que nos ocupamos neste estudo, resta-nos ainda a árdua tarefa de garimpar, nas obras lexicográficas disponíveis, algum registro ou abonação de seu emprego com preposição e com infinitivo, tal como registrado no século I da Era Cristã. Embora não tenhamos encontrado tais registros em dicionários de latim, pudemos localizar notações a esse respeito na obra $A$ new and copious lexicon of the Latin language, que reproduzimos a seguir:

\section{FIGURA 1: Verbete damnum}

DĀMNס̄ (damnum), as, āvi, ātum, a. 1. to condemn, to sentence, катокрivtu, ката-

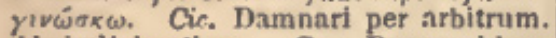
Id. judicio aliquo. Cas. Damnari lege Pompla. II With the ablatice or genitioe of the crime, or with a preposition. Cic. Damnare aliquem sceleris. Id. quempiam aliquo crimine. Id, Dainnari nomine sceleris. Id. de pecuniis repetundis. Id. Inter sicarios, for murder. Id. pro socio, for breach of trust. Ooid. In aliqua re. Sueton. ob aliquam rem. Cos. Damnare capitis, to condemr to death. With the ablative, dative, or genitive of the punishment, or with a preposition. Auct, ad Herenn. capite. Sueton. ad opus, to hard labor. Pondect. In metallum, in opus publicum, ad bestias, to sentence to the mines, sc. Ovid. Damnari in unam partem. Pandect. Damnare ultimo supplicio, to sentence to condign punishment. Cic. aliquein octupli. Gell. aliquem pecunia, to fine in a certain sum of money.
Lucret. morti. Justin. Damnari jecunia. - With the infinitice. Horat. Dimnati dare populo centum paria gladiatorum. - की Also, to bind, oblige. Pandect. - II Figur. to condemn, dislike, divapprove, rcject, throw avide. Quintil. Librus damnare. Lucan. Damnare congilinun alicnjus. Plin. Arbores ad occasus seri damnavit, did not allow. Id. A.l laborem damnantur, are considered unfit for. Stat. Damnavit vesci, refused to lake nourishment. - If Also, to destine, doom. Virz. Caput damnaverat Orco. - I Also, to make liable, to oblige to perforin. - Ilence, Damnare homines voti or votis, to grant their request, becanse they are thus laid under an obligation to fulfil their voros. Firg. dumnabis tu quoque votis, thou shalt bind (thy suppliants) by vonos, b. e. to perfurm their vows (hy granting their prayers;. Lio. Precibintur, ut dinmnarentur votoruin, A. $\epsilon$. that their prayers misht be granted.

Fonte: LeLEVERETT, 1842, p. 232. Fac-similada.

De acordo com as informações registradas no verbete damnum fonte primária do verbo damnare, segundo nos ensinam os etimologistas consultados -, empregava-se tal verbo com a preposição quando seu argumento interno era expresso por determinados substantivos 
flexionados nos casos ablativo, dativo ou genitivo de crime. ${ }^{7} \mathrm{O}$ infinitivo empregado como verbo principal, por seu turno, é registrado inicialmente com uma abonação de Horácio:

(7) "Damnati dare populo centum paria gladiatorum" (Condenados a dar ao povo cem pares de gladiadores)

[Damna-

[Condenar

popul-

povo

gladiat-

gladiador -ti da-

particípio passado plural

centum

cem (invariável)

-orum]

genitivo plural]

Conforme se depreende da tradução e da glosa, apesar de o verbo danar já figurar em uma perífrase verbal, trata-se de uma construção distinta daquela aspectual ilustrada de (1) a (4). Na abonação extraída de Horácio, o verbo danar, embora apareça como primeiro elemento da construção, não se comporta, ainda, como um verbo auxiliar, dado que está flexionado no particípio passado e, como forma nominal que é, ainda preserva tanto seu valor semântico, quanto a propriedade de selecionar argumentos. Nesse contexto, o infinitivo satisfaz, portanto, as exigências argumentais de danar flexionado no particípio passado, que é um predicador nominal.

Outros usos são ainda registrados para o emprego da forma com o infinitivo: (i) marcar empregos figurados do verbo, entre os quais se cita condenar ${ }^{8}$ no sentido de "desaprovar" ou de "vetar permissão"; (ii) marcar a função gramatical de tempo, em construções como a que se glosa em (8), extraída do verbete por nós reproduzido:

\footnotetext{
${ }^{7}$ Note-se que não há referência ao emprego da preposição com o caso acusativo, tal como ilustrado em (5). Outro aspecto digno de nota é que a abonação apresentada pelos autores (ad opus) emprega o nome neutro opus flexionado no acusativo.

${ }^{8}$ Essa abonação alinha-se com os sentidos etimológicos propostos por Nascentes (1933) e por Cunha (1997), diferindo-se daqueles propostos por Machado (1987), que considera este um dos sentidos etimológicos do item.
} 
(8) Damnavit vesci (condenou 9 a alimentar)

[Damnav- - -it vesc- $\quad$-i]

[Condenar perfectum ${ }^{1} \quad 3^{\text {a }}$ p. pret. perf. ind. alimentar infinit. pres. depoente]

e (iii) exprimir a modalidade deôntica orientada para o agente, que, de acordo com Bybee, Perkins e Pagliuca (1994), é semanticamente expressa pelas noções de obrigação e de necessidade, ${ }^{11}$ como se ilustra em (9), com uma abonação também extraída do verbete reproduzido:

(9) Damnare homines votis (Obrigar os homens (a cumprir(em)) um voto/ promessa.)

$\begin{array}{lccc}\text { [Damna- } & \text {-re } & \text { homin- } & \text {-es } \\ \text { [Obrigar } & \text { infinitivo presente } & \text { homem } & \text { acusativo plural } \\ \text { vot- } & \text {-is }] & & \\ \text { voto/promessa } & \text { genitivo plural }] & & \end{array}$

${ }^{9}$ É possível também, dependendo do contexto, traduzir o verbo danar como recusar (recusou-se a alimentar), tal como mencionado no verbete. No contexto original de onde se extraiu o verbete (Silius Italicus, Punica liber quintus, v. 62), essa é a tradução mais adequada, já que se trata de um contexto religioso em que o personagem se recusa a comer.

${ }^{10}$ Faria (1958) nos ensina que o tema do perfectum expressa uma ação concluída, completa, o que evoca, sem dúvida, uma conotação aspectual, tributária do indoeuropeu. Adverte-nos, contudo, de que "uma das grandes inovações realizadas pela conjugação latina foi substituir a noção de aspecto, peculiar [...] ao verbo indo-europeu, pela noção de tempo, que vai aparecer tanto no infectum como no perfectum, em seus diversos modos" (FARIA, 1958, p. 229, grifos nossos, exceto em infectum e pecfectum). Disso se depreende que, de fato, a construção latina damnavit vesci já funcionava como um marcador temporal, não apenas pela morfologia do pretérito (-it), mas também pela própria essência do tema de perfectum

${ }^{11}$ Segundo esses autores, a obrigação reporta a existência de fatores externos (condições sociais) que obrigam um agente a realizar a ação expressa pelo predicado, enquanto a necessidade é impelida por fatores internos (condições psicológicas). 
Os registros latinos ora analisados nos possibilitam identificar, portanto, apenas duas funções gramaticais para o verbo danar nesta língua: (i) marcador temporal e (ii) marcador de modalidade. A ausência de uma abonação que nos permita reconhecer a função aspectual de danar leva-nos a inferir que, embora já existisse a construção sintática de $\mathrm{V} 1_{\text {danar }}$ $+V 2_{\text {infinitivo }}$ na língua latina, esta não era ainda aspectual, função gramatical que, de fato, surgiu em um estágio posterior da língua. Tal generalização, contudo, contraria a trajetória universal de gramaticalização da categoria TAM (tempo, aspecto e modalidade), proposta por Bybee (1985). Cabenos, pois, a partir das informações etimológicas obtidas e da constatação de que a construção aspectual é mais recente na língua, tentar estabelecer a relação de herança entre as construções identificadas no latim e a contemporânea, bem como explicar a possível contradição de nossos resultados em relação à trajetória de gramaticalização de TAM, tarefa a que nos dedicaremos na seção subsequente.

\section{A relação de herança entre construções latinas e portuguesas: em busca do elo perdido}

As pesquisas diacrônicas e lexicográficas empreendidas nos permitiram identificar dois contextos sintáticos potenciais para a gênese da construção aspectual contemporânea formada por $\mathrm{V} 1_{\text {danar }}+$ (prep) $+\mathrm{V} 2_{\text {infinitivo }}$ Assim, para estabelecermos uma possível relação de herança entre tais contextos, como nos propusemos a fazer, será necessário combinar tanto fatores sintáticos quanto semânticos e cognitivos. Procederemos a essa tarefa com a análise dos fatores sintáticos: acreditamos que a preposição presente na construção seja uma reminiscência do caso acusativo latino, mais especificamente do acusativo de movimento e do acusativo de extensão, ${ }^{12}$ os quais conferem a função cumulativa à construção. Embora o acusativo seja geralmente empregado para indicar o objeto sobre o qual se dirige a ação verbal, este não era, segundo nos ensina Faria (1958, p. 60, grifos nossos),

\footnotetext{
${ }^{12}$ Havia na língua latina sete tipos de acusativo: (i) acusativo de objeto, (ii) acusativo interno, (iii) duplo acusativo, (iv) acusativo de movimento, (v) acusativo de extensão, (vi) acusativo de relação e (vii) acusativo exclamativo. Para informações mais detalhadas acerca das funções de cada especificidade do caso, consultar Faria (1958, p. 334-340).
} 
seu valor primitivo, tendo sido empregado, a princípio, independentemente do verbo, o que explica as suas construções com verbos intransitivos, ou como duplo acusativo. Outro emprêgo freqüente é indicar a extensão no tempo ou no espaço, bem como caracterizar o têrmo de um movimento, empregos êstes em que se generalizou o uso das preposições, embora se conserve uma ou outra construção que as dispense.

Nas construções em que se empregavam preposições, estas eram normalmente $a d$ (para o acusativo de movimento) e per (para o acusativo de extensão). ${ }^{13}$ De acordo com Said Ali (2001, p. 160, grifos nossos, exceto nas preposições), ${ }^{14}$ "a partícula $a d$ começou a usar-se em latim para enunciar o conceito de direção ou movimento para algum ponto, de aproximação e final junção de uma coisa a outra. Esse mesmo sentido vive em nossa preposição $a$, apesar da concorrência de para, que lhe cerceia por vezes o emprego". Ainda segundo o autor, "tinha per [...] o valor de 'através de', 'por meio de' e podia significar 'lugar por onde' alguma coisa se estende e duração 'de algum acontecimento" (SAID ALI, 2001, p. 163, grifos nossos). Como se depreende das notações de Faria (1958) e de Said Ali (2001), o movimento e a duração expressos pela construção $\mathrm{V} 1_{\text {danar }}+$ (prep) já traduziam, desde a origem, uma direção indeterminada no tempo, tal como se observa na construção aspectual analisada por nós, em que não se demarca nenhum contorno do estágio final de duração do evento expresso por V2. Essa ausência de demarcação de fim e consequente duração do evento decorrem de outra função do acusativo, denominado de acusativo de extensão:

o acusativo tinha ainda por função indicar a extensão no tempo e no espaço. No tempo, essa ideia de extensão se traduz precipuamente pelo sentido de duração. Para

\footnotetext{
${ }^{13}$ A preposição in é também muito produtiva com o acusativo. Como seu emprego visava a um preciosismo semântico, a distinção de uso está no tipo de movimento que se pretendia expressar. Segundo Ravizza (1940), tais preposições indicam um movimento em direção a algum lugar; um movimento locativo, portanto. A distinção básica no emprego de $a d$ e in está no alcance do movimento expresso: ad marca um movimento até junto de; in marca um movimento até dentro de. No caso das construções analisadas, in não ocorria por traduzir um movimento interno.

${ }^{14}$ Originalmente publicado em 1921.
} 
indicar que a duração é ininterrupta, os autores latinos costumam usar o acusativo precedido da preposição per (FARIA, 1958, p. 339, grifos nossos, exceto na preposição).

Além da explicação para o fato de a construção $\mathrm{V} 1_{\text {danar }}+$ (prep) $+\mathrm{V} 2_{\text {infinitivo }}$ expressar cumulativamente tanto o movimento inicial do evento, quanto sua duração ininterrupta, outra questão teórica que pode ser elucidada, tomando-se em conta os ensinamentos do gramático latino, é a opcionalidade da preposição na construção aspectual contemporânea: João danou (a) falar de religião. Como o emprego da preposição não era, na língua latina, uma exigência sintática, mas um preciosismo semântico, esta podia ou não ocorrer, tendência preservada ainda hoje, sobretudo nos contextos de oralidade: "em latim, mesmo no período clássico, ainda se conservam vestígios do primitivo estado de coisas em algumas construções que dispensam as preposições, como por exemplo, [...] construções de verbos de movimento com o acusativo do supino" (FARIA, 1958, p. 338, grifos nossos).

Em relação aos fatores semânticos, sobretudo no que diz respeito aos traços semânticos remanescentes nos atuais usos de danar e que são oriundos do latim, é interessante observar que os sentidos de duração e de intensidade perpassam as construções aspectuais com danar. Expressões tão comuns no português contemporâneo, como "trabalhar feito um condenado", "comer como um condenado", "chorar tal como um condenado", entre outras, remetem ao sentido de "condenar" e à semântica da duração e da intensidade que esse sentido evoca, já que aquele que é condenado a algo deve se dedicar ao cumprimento de sua sentença por um longo período e de modo intenso. Assim, "trabalhar feito um condenado" corresponde a trabalhar muito. Sentido equivalente é ainda identificado em expressões como "trabalhou pra danar", "comeu pra danar", "chorou pra danar". Esses exemplos evidenciam que, embora o sentido da construção não seja composicional, conforme defende Goldberg (1995), ele pode ser influenciado - e normalmente o é (cf. princípio da persistência (HOPPER, 1991)) - pelos esquemas cognitivos subjacentes à etimologia das formas que a compõem.

Para tentarmos mapear os fatores cognitivos envolvidos na emergência da construção aspectual $\mathrm{V} 1_{\text {danar }}+($ prep $)+V 2_{\text {infinitivo }}$ a partir dos contextos sintáticos e dos significados já identificados no latim, embasarnos-emos, como já sinalizado nas considerações iniciais, nos pressupostos 
da Linguística Cognitiva. Para essa abordagem teórica, as significações gramaticais, bem como todas as outras significações abstratas, são projeções figurativas dos esquemas conceptuais primários que estruturam as experiências humanas mais básicas. Desse modo, estamos assumindo que a noção abstrata que, a partir do século XX, permite às construções encabeçadas pelo verbo danar expressar as noções aspectuais inceptiva e durativa pode ser interpretada também ${ }^{15}$ como uma projeção figurativa da experiência humana primária, básica, corpórea, nomeada pelo verbo danar ainda no latim - o ato da condenação.

Todo ato de condenação pressupõe, em seu frame, aquele que condena e aquele que é condenado a algo (a pena), o que podemos interpretar como um embate de forças, dado que um deles (aquele que condena) impõe uma força (a pena ou punição) a outro (o condenado). No que diz respeito à força, os trabalhos de Talmy $(1988,2000)$ são extremamente relevantes para a Linguística Cognitiva, por tratarem da emergência de expressões linguísticas a partir de esquemas relativos à aplicação de forças no domínio físico, básico, corpóreo, tal como estamos propondo. Esses esquemas abrangem os conceitos de agonista e de antagonista, sendo este a entidade que exerce a força e aquele, a entidade que recebe a força aplicada. Passemos à ilustração desses conceitos, tomando como exemplo o verbo danar, no sentido de "condenar", tal como empregado nestas duas construções latinas:

(10) Damnare ad bestias (condenar às feras)

[Damna- -re ad besti- as

[Condenar infinitivo presente preposição $a$ fera acusativo plural]

(11) Damnare ad opus (condenar a trabalhos)

[Damna- - - $\quad$ ad $\quad$ op- $\quad$-us]

[Condenar infinitivo presente preposição $a$ trabalho acusativo plural]

${ }^{15}$ Para além da herança sintática do acusativo latino, à qual se agregam fatores semânticos, questões de natureza cognitiva concorrem, igualmente, para o valor cumulativo da construção aspectual. 
$\mathrm{Na}$ experiência física de se condenar às feras (cf. (10)), há uma luta de forças entre aquele que foi condenado a ser literalmente jogado às feras (o que, de fato, acontecia no Império Romano) - o agonista - $\mathrm{e}$ aquele que era encarregado de executar tal condenação - o antagonista. Em se tratando da condenação ao trabalho (cf. (11)), deparamo-nos com um uso mais abstrato da forma verbal, mas podemos ainda entender a pena como uma força aplicada ao réu, que não tem controle sobre tal situação. Conforme já argumentamos, acreditamos que essa falta de controle é projetada figurativamente nas construções com $\mathrm{V} 1_{\text {danar }}$ já que quem dana a chorar, por exemplo, não tem, normalmente, controle psicológico sobre essa ação. Por trás dessas cenas evocadas no ato de condenação e dessa dinâmica de forças subjacente a esses atos de execução, temos também a duração das penas, que acreditamos estar figurativamente projetada na duração do evento expresso por $\mathrm{V} 2_{\text {infinitivo }}$. Conforme defendido por Paula (2014), a construção aspectual V1 $1_{\text {danar }}^{\text {infitivo }}+$ (prep) $+\mathrm{V} 2_{\text {infinitivo }}$ marca não apenas o início de um evento, mas também sua duração no eixo do tempo, por onde tal evento se desloca (transcorre) metaforicamente. E, no plano cognitivo, isso é possível graças aos esquemas de força e de movimento, que, conforme demonstramos, subjazem os sentidos mais básicos de danar.

Segundo o modelo de interação de forças proposto por Talmy (2000), no domínio linguístico, a dinâmica de forças envolve quatro dimensões básicas: (i) as entidades de força (agonista vs. antagonista); (ii) a tendência intrínseca da força (para o movimento vs. para o repouso); (iii) o resultado da interação de forças (movimento vs. repouso); e (iv) o equilíbrio de forças (entidade mais forte vs. entidade mais fraca). Assim, a noção de movimento seria intrínseca nos casos de interação de força. $\mathrm{Na}$ experiência física de ser condenado às feras (cf. (10)), identifica-se um movimento daquele que é condenado em direção aos animais. Essa experiência física de condenação pressupõe, portanto, um movimento causado pela entidade mais forte (aquela que condena). Se X condena $\mathrm{Y}$ às feras, $\mathrm{X}$ faz com que $\mathrm{Y}$ se desloque (movimente) em direção aos animais (jogado em uma jaula ou ao centro do Coliseu, por exemplo). Assim como prevê a noção de movimento causado de Goldberg (1995), $X$ (o agonista) faz com que $Y$ (o antagonista) se desloque para Z (o lugar da condenação). Também no sentido de "condenação ao trabalho" (cf. (11)), há o deslocamento/movimento para o local de cumprimento da pena. Vê-se, portanto, que o esquema imagético de movimento subjaz 
as construções latinas mais antigas. Esse esquema conceptual primário de movimento, estruturado na experiência física, básica, é projetado figurativamente na significação gramatical do acusativo de movimento do verbo danar, conforme se verifica em Faria (1958). Em virtude do processo de abstração por que passam os semas no curso da língua, nos demais sentidos, a noção de movimento se manifesta mais abstratamente, levando-se em conta a metáfora "mudança é movimento" (KÖVECSES, 2010, p. 370, tradução nossa).

Nos sentidos apresentados pelos dicionários etimológicos, não se tem um movimento físico/espacial, mas todos pressupõem uma mudança no paciente, que é afetado pela ação de um referente-sujeito que controla o estado em que o paciente passa a se encontrar, como revelam as seguintes estruturas argumentais: X prejudicar Y; X irritar Y; X encolerizar Y; $\mathrm{X}$ condenar (em justiça) $\mathrm{Y}$ - para os sentidos apresentados por Cunha (1997) -; X declarar Y (como) culpado; X obrigar Y (a W); X censurar Y; X criticar Y - para os sentidos citados por Machado (1987).

É importante registrar que dessas relações de força origina-se a proposta talmyana da modalidade deôntica, a qual resulta do embate de forças entre um agonista (entidade obrigada a agir, habilitada a agir ou impedida de agir) e um antagonista (entidade sensível e consciente). Conforme defende Talmy (2000), a categoria semântica que mais prototipicamente caracteriza a modalidade é a dinâmica de forças. Esse raciocínio explica o uso modal deôntico ${ }^{16}$ do verbo danar ainda no latim, conforme se identifica no verbete extraído da obra $A$ new and copious lexicon of the Latin language e reproduzido na primeira seção deste texto (cf. Figura 1).

Como registrado nessa obra lexicográfica e já demonstrado por nós, além do valor modal, o auxiliar danar marcava também, já no latim, a categoria de tempo (cf. (8)), registros que nos colocam em condição de tentar reconstruir o percurso de mudança do verbo danar como um marcador aspectual no português contemporâneo. Tais registros diacrônicos, contudo, não nos habilitam a estabelecer uma cronologia precisa em relação às categorias de tempo e de modalidade, já que os

${ }^{16}$ Como defendido por Bybee, Perkins e Pagliuca (1994), no caso da modalidade deôntica orientada para o agente, tal como identificado nas abonações latinas, atua uma força externa, o que pode ser comprovado pela ação do antagonista (sujeito agente) sobre o agonista (paciente). 
contextos descritos indicam tão somente que as construções modais e temporais já existiam no latim e que, segundo dados de Paula (2014), a construção aspectual emergiu no século XX, sendo, portanto, a última categoria a se gramaticalizar. Como já sinalizado, tal cronologia, ainda que indefinida em relação às duas categorias gramaticais identificadas no latim, contraria o continuum de gramaticalização proposto por Bybee (1985), que, a partir da análise de um conjunto de cinquenta línguas, identifica a seguinte tendência universal de gramaticalização da categoria TAM: ASPECTO - TEMPO - MODALIDADE. Frente a esse dado, cumpre-nos advertir o leitor de que tal categorização é, como a própria autora sinaliza, uma tendência, contra a qual já existem outros contraexemplos, especialmente em línguas crioulas e em pidgins, conforme demonstrou Bickerton (1974), citado por ela. ${ }^{17}$ Ademais, há de se considerar que a cronologia proposta por Bybee (1985) diz respeito, mais estritamente, aos recursos morfológicos para expressão da categoria TAM, além de prever especificidade para a modalidade orientada para o agente, como se infere desta consideração acerca das discrepâncias identificadas para os crioulos:

o problema reside apenas na tentativa de se equiparar modo flexional com modalidade não-flexional. [...] o modo flexional raramente expressa noções deônticas ou outras noções que nós chamamos de modalidade orientada para o agente. Notamos também que as modalidades orientadas para o agente se desenvolvem diacronicamente em epistêmica e outros modos, e tempos futuros. Como isso ocorre, as distinções temporais marcadas nos modais tendem a se perder ou a ser interpretadas como distinções não temporais (BYBEE, 1985, p. 197, tradução nossa). ${ }^{18}$

${ }^{17}$ Segundo Bybee (1985), Bickerton (1974) estudou a função e a ordenação de elementos pré-verbais de várias línguas pidgin e crioulas e concluiu que TEMPO MODALIDADE - ASPECTO é a ordem universal de tais línguas.

18 " The problem lies solely in the attempt to equate inflectional mood and non-inflectional modality. [...] inflectional mood rarely expresses deontic notions or other notions we have called agent-oriented modalities. We have also noted that the agent-oriented modalities develop diachronically into epistemic and other moods, and future tenses. As this happens, tense distinctions marked on modals tend to be lost, or reinterpreted as non-temporal distinctions". 
Dando sequência à análise dos contraexemplos identificados por Bickerton (1974 apud BYBEE, 1985), a autora admite a dificuldade de se lidar com os dados das línguas crioulas, principalmente porque seus elementos pré-verbais advêm de diversas fontes, além de se encontrarem em diferentes estágios de desenvolvimento, mas chama a atenção para a especificidade dos morfemas aos quais Bickerton (1974 apud BYBEE, 1985) se refere como modais. Segundo ela, tais morfemas traduzem a modalidade orientada para o agente, tal como identificado por nós na língua latina. Assim, a pesquisadora conclui que a mudança na ordem das categorias reside na interação entre tempo, modalidade e modo. Os marcadores de modalidade, segundo ela, desenvolvem-se, muito frequentemente, de verbos principais - caso também do nosso estudo -, que são originalmente marcados para tempo. Entretanto, como os auxiliares modais tendem a perder o sentido de orientação para o agente, tornando-se epistêmicos, eles não podem mais ser modificados pela categoria tempo. Outro aspecto que pode interferir nessa ordenação é a própria configuração sintática das línguas. Bybee (1985, p. 200, tradução nossa) observa que "em línguas $\mathrm{OV}$, as marcas temporais serão um sufixo, o que resulta na ordem VERBO - MODALIDADE - TEMPO. Em línguas $\mathrm{VO}$, os marcadores temporais são mais susceptíveis de ser préverbais, resultando na ordem TEMPO - MODALIDADE - VERBO". ${ }^{19}$ A julgar por nossos dados, a língua portuguesa foge à tendência universal no tocante à categoria TAM e assemelha-se às línguas crioulas, em que aspecto é uma categoria menos relevante. Assim, considerando-se tratar de uma língua $\mathrm{VO}$, a escala de relevância da categoria TAM na língua portuguesa parece delinear-se deste modo: TEMPO - MODALIDADE - ASPECTO. Isso significa que, na composição do sentido global da construção, tempo é mais relevante que modalidade, que, por sua vez, é mais relevante que aspecto. No entanto, considerando-se que os dados da língua latina não nos permitiram identificar a precedência diacrônica das categorias de tempo e de modalidade, essa proposta de ordenação ainda carece de investigações diacrônicas mais contundentes, o que abre precedente para pesquisas futuras.

\footnotetext{
19 "In OV languages, the tense marker will be a suffix, so that the order VERB - MODAL - TENSE results. In VO languages, the tense markers are more likely to be pre-verbal, yielding the order TENSE - MODAL - VERB”.
} 
Delimitado o percurso da mudança e assumindo, conforme Goldberg (1995), que as construções linguísticas se associam por relações de herança, cabe-nos, por fim, tentar estabelecer tais relações. Cotejando as semelhanças entre as duas construções que já figuravam no século I, no latim, e a construção aspectual emergente no século XX, parece-nos que esta herdou parcialmente traços da sintaxe e da semântica daquelas que a antecederam diacronicamente. Apoiando-nos em Fauconnier e Turner (c1998), estamos assumindo que a terceira construção, isto é, a construção aspectual, emergiu de uma mesclagem conceptual das duas outras, que a precederam na história da língua. Como já demonstrado, apesar de separadas por um intervalo temporal que atravessou vários séculos, as três são construções análogas em aspectos sintáticos e semânticos e, para Fauconnier e Turner (c1998), construções análogas podem ser adequadamente analisadas por meio da teoria da mesclagem conceptual. Acreditamos, assim, que essas estruturas análogas compõem os espaços de entrada a partir dos quais há a projeção da estrutura conceptual selecionada para o espaço mescla. Nesse espaço há, então, a integração em estrutura parcialmente emergente. Esse processamento implica, portanto, no mínimo, dois domínios de conhecimento (inputs): um domínio chamado espaço genérico, que reflete as estruturas dos inputs (espaços de entrada), e outro domínio, o espaço mescla, que combina propriedades dos inputs e no qual se apresenta a estrutura emergente (FAUCONNIER, 1997). A figura a seguir visa a representar esse processo, tal como o estamos concebendo: 
FIGURA 2: Esquema imagético da teoria da mesclagem

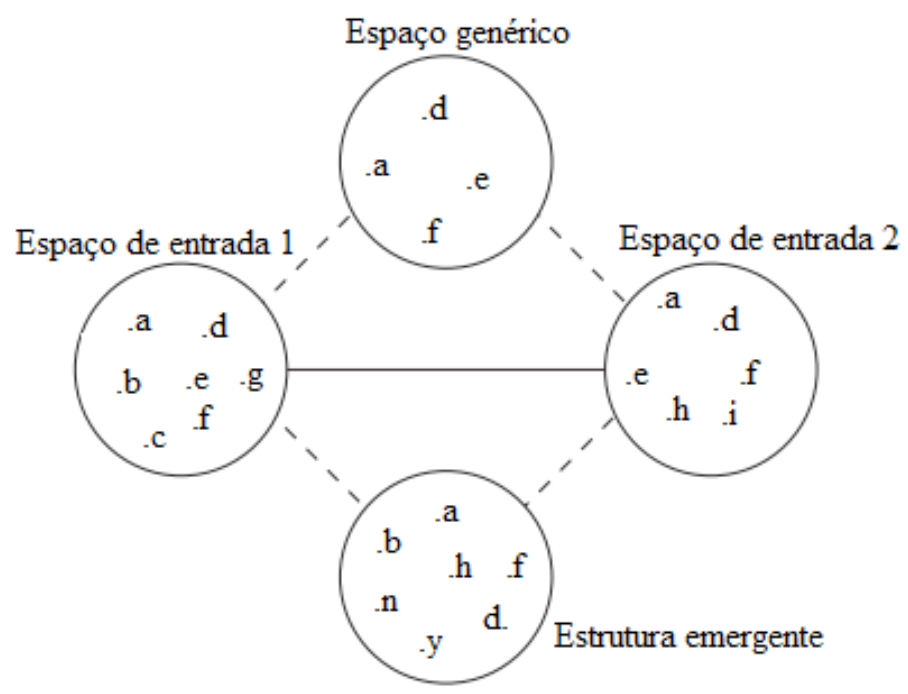

Fonte: Adaptado de Tenuta (2010).

Nessa abordagem cognitivista, uma estrutura aparentemente simples, como "Maria danou (a) falar", por exemplo, pode se mostrar não tão simples ao analisarmos a configuração de espaços necessários para a construção do seu significado. A teoria da mesclagem, representada na figura acima, pode auxiliar-nos a entender o que acontece cognitivamente, quando processamos certos enunciados desse tipo.

A mesclagem é um tipo de processamento cognitivo recorrente em um grande número de situações: em estruturas narrativas, na elaboração de significados de palavras, na elaboração de significados de sentenças, em metáforas e em estruturas sintáticas, como é nosso caso no âmbito deste estudo. Trata-se, portanto, de um procedimento produtivo e empregado para propósitos variados. Com a finalidade de entender a configuração sintática e semântica da construção aspectual V1 ${ }_{\text {danar }}+($ prep $)+V 2_{\text {infinitivo }}$, optamos por adotar essa teoria, não só porque as construções envolvidas na relação de herança são análogas, mas também porque a mesclagem é um tipo de processamento mental em que o significado gerado não se restringe à mera soma do significado dos elementos envolvidos na sua composição, o que se alinha ao conceito de construção, concebida como 
pareamento de forma e de significado, tal como proposto por Goldberg (1995). Tenuta (2010, p. 95) nos fornece um exemplo de mesclagem operando no nível da sintaxe no português contemporâneo:

Tomemos a seguinte frase: "Ela estudou os filhos até a quarta série". Tal estrutura sintática do português brasileiro pode ser compreendida como uma mesclagem conceptual que envolve [Ela criou os filhos. Eles estudaram até a quarta série.], havendo uma relação de resultado entre esses eventos. O verbo "estudar" especifica uma ação de "os filhos", ação essa que, por sua vez, é um resultado de uma ação de "ela". No entanto, o verbo "estudar" tem como sujeito sintático "ela":

SN1 V1 SN2 (Ela criou os filhos.)

SN2 V2 Sprep (Os filhos estudaram até a quarta série.)

Há, então, seleção de elementos, gerando a seguinte construção resultativa mesclada:

SN1 V2 SN2 Sprep.

Analogicamente a esse raciocínio, estamos propondo que a construção aspectual $\mathrm{V} 1_{\text {danạr }}+($ prep $)+V 2_{\text {infinitivo }}$ origina-se de duas construções do latim, as quais, com semelhanças formais e esquemas de movimento e de forças comuns subjacentes, mesclam-se, resultando numa nova construção, com um novo pareamento forma-significado, mas que mantém alguns traços sintáticos e semânticos da forma-fonte, conforme propõe o princípio da persistência, concebido por Hopper (1991). Sobre a gramaticalização, processo de mudança responsável por permitir que o verbo danar assuma, no curso da língua, a função gramatical de marcador de tempo, de modalidade e de aspecto, respectivamente, Tomasello (2003, p. 5, grifos nossos, tradução nossa) entende que "a dimensão gramatical da língua é um produto de um conjunto de processos históricos e ontogenéticos chamados, coletivamente, de gramaticalização". ${ }^{20}$ Acreditamos que, nesse processo histórico e ontogenético de emergência e de desenvolvimento da construção aspectual V1 $1_{\text {danar }}+($ prep $)+V 2_{\text {infinitivo, }}$ o processo de mesclagem atuou tal como ilustrado na figura a seguir:

20 " [...] the grammatical dimension of language is a product of a set of historical and ontogenetic process referred to collectively as grammaticalization". 
FIGURA 3: Esquema imagético do processo de mesclagem do verbo danar

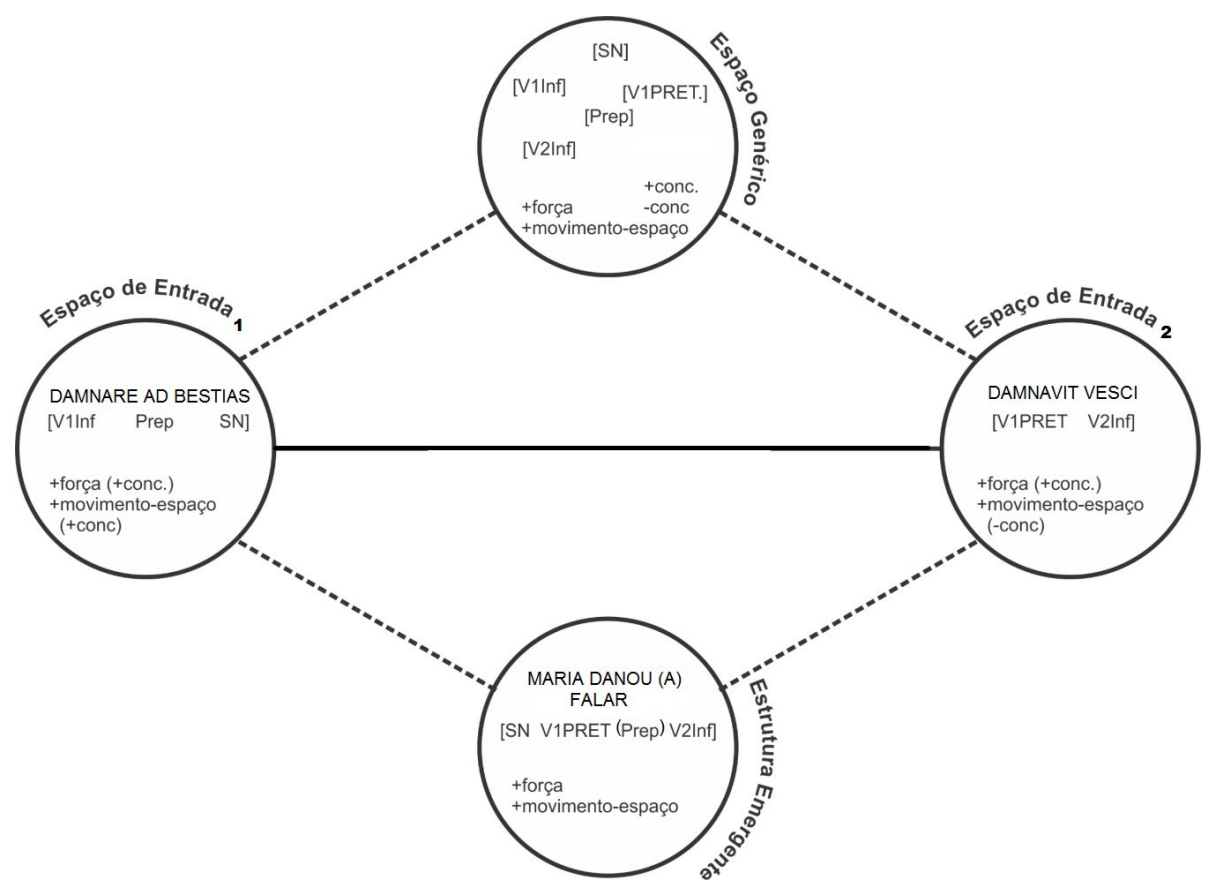

O processo cognitivo da mesclagem é capaz de amalgamar heranças de múltiplas construções. Na representação imagética apresentada, os espaços de entrada 1 e 2 representam os domínios-fonte que contribuem para a formação da estrutura aspectual emergente. Eles contêm os elementos sintáticos e semânticos a serem selecionados e projetados na mescla, os quais resultam na composição de uma nova estrutura integrada no espaço genérico. No espaço de entrada 1, temos a construção latina "damnare ad bestias" com a seguinte estrutura sintática: [V1 $1_{\text {infinitivo }}+$ prep $+\mathrm{SN}$ ]. Em sua semântica, temos a relação de força - uma força mais concreta que aquela subjacente a outros sentidos de danar, porque, como já demonstrado, podemos perceber, na situação de "jogar alguém às feras", a atuação de uma força realmente física, concreta, de um antagonista que, numa ação física, puxa e empurra um agonista em direção a essas feras. A preposição é, conforme argumentado, a unidade sintática que, precedendo o acusativo latino, traduz semanticamente o movimento do agonista na direção imposta pelo antagonista. Sua omissão é possível, porque 
se trata de um preciosismo semântico, já que o esquema imagético de movimento é também subjacente aos sentidos de damnare: num esquema de forças, a atuação de um antagonista sobre um agonista pressupõe sempre movimento, a não ser naquela situação em que o agonista impede o movimento do antagonista. Assim, o esquema imagético de movimento é intrínseco ao da força. Na cena evocada por "damnare ad bestias", há, pois, o movimento do réu num percurso em direção às feras, o que se reflete na marcação do movimento inicial do evento, que configura o aspecto inceptivo na construção tributária da mescla.

No espaço de entrada 2, temos a construção latina "damnati vesci" (condenou a comer/alimentar) cuja estrutura sintática é [V1 $1_{\text {finito }}$ $+\mathrm{V} 2_{\text {infinitivo }}$. Nessa construção, já temos um V1 conjugado no tempo pretérito, que é o tempo em que danar aparece prioritariamente na construção aspectual contemporânea, conforme dados de Paula (2014), e o V2 infinitivo também. Em relação à dinâmica de forças, temos um agonista que tenta ir contra a força aplicada pelo antagonista. Temos, então, um movimento de oposição de forças, menos concreto, sem dúvida, do que aquele que é visível no deslocamento do agonista na cena do espaço de entrada 1.

No espaço genérico, temos refletidos os inputs de 1 e de 2: as noções de movimento e de força, a combinação de V1 e de V2, a presença do SN e da preposição, que corrobora a ideia de movimento direcional do caso acusativo latino. A combinação desses espaços resulta na estrutura emergente $\mathrm{V} 1_{\text {danar }}+$ (prep) $+\mathrm{V} 2_{\text {infinitivo }}$ representada, na figura, por "Maria danou (a) falar", $\left[\mathrm{SN}+\mathrm{V} 1_{\text {prẹtérito }}+\right.$ (prep) $\left.+\mathrm{V} 2_{\text {infinitivo }}\right]$. Essa construção origina-se, portanto, da combinação de um SN presente no espaço 1, com o $V 1_{\text {finito }}$ do espaço 2, mais a preposição presente no espaço 1 - que, como vimos, pode ser ou não dispensada - e o V2 ${ }_{\text {infinitivo }}$ presente no espaço 2. Na cena evocada por "Maria danou (a) falar", conforme apresentado por Paula (2014), os esquemas de movimento e de força são mais abstratos. Para compreendê-los, é necessário considerar a clássica metáfora “tempo é espaço", proposta por Lakoff e Johnson (2002), a qual implica admitir que deslocamentos no espaço correspondem a deslocamentos no eixo temporal. O esquema imagético de movimento está presente no deslocamento/movimento da ação no tempo metaforizado como espaço. O esquema dinâmico de força, aliado ao acusativo de extensão, é, assim, o que permite a intensidade da ação de V2; afinal, quem "dana a falar" fala com intensidade (força), fala muito. 
Esses aspectos cognitivos subjacentes às construções com danar desde o latim ajudam-nos, portanto, a entender a emergência da construção aspectual com danar no século XX por meio do processo de mesclagem cujos traços têm raízes na história e na ontogênese desse item desde o século I da Era Cristã. A despeito de a teoria da mesclagem não ser normalmente adotada para descrever fenômenos diacrônicos, não podemos perder de vista, especialmente numa perspectiva analítica, que, tal como defende Bybee (2012), os mecanismos linguísticos são universais e que sua aplicação cria caminhos comuns de mudança. Nesse sentido, cada período de tempo e cada língua são únicos, mas partilham entre si muitas propriedades comuns, porque são criados pelas mesmas forças que atuam em contextos semelhantes, ou seja, as forças que atuam no presente são, teoricamente, as mesmas que atuaram no passado. Nessa perspectiva, nosso entendimento é de que as construções aspectuais por nós analisadas são produto de relações de herança sintática e semântica de sincronias pretéritas latentes nas formas hoje em uso.

\section{Considerações finais}

Este texto se dedicou a verificar se as construções formadas por $\mathrm{V} 1_{\text {danar }}+($ prep $)+\mathrm{V} 2_{\text {infinitivo }}$ emergiram na contemporaneidade para expressar aspecto inceptivo com prolongamento de ação na língua portuguesa ou se, à semelhança de padrões sintáticos análogos, representados por $\mathrm{V} 1_{\text {danar }}$ + prep $+\mathrm{SN}$ e por $\mathrm{V} 1_{\text {danar }}+\mathrm{V} 2_{\text {infinitivo }}$ e registrados na língua latina desde o século I da Era Cristã, são construções que estiveram em estado de latência, já que seu primeiro registro em corpora é identificado somente no século XX. Apoiando-nos no quadro teórico da Linguística Cognitiva e da Gramática de Construções, buscamos também estabelecer a relação de herança por extensão metafórica entre as construções do século I e aquela identificada no século XX.

Uma incursão pela etimologia do verbo danar permitiu-nos identificar não só a origem latina da forma, como também seus sentidos concretos e abstratos, o que já explica, em parte, as semelhanças de uso entre as construções analisadas, a despeito da distância cronológica que as separa. Constatamos também que, na língua latina, as construções com o verbo damnare expressavam apenas tempo e modalidade e que, portanto, a construção aspectual emergiu na contemporaneidade, o que aproxima a língua portuguesa das línguas crioulas no tocante à ordenação da categoria TAM: TEMPO - MODALIDADE - ASPECTO. 
Essa constatação não aponta, contudo, para uma inovação do sistema linguístico, já que é possível estabelecer uma relação de herança de padrões entre as formas análogas. Entendemos que a construção aspectual contemporânea é, na verdade, o resultado de uma mescla entre as construções identificadas no século I, das quais herdou tanto o padrão sintático de $\mathrm{V} 1_{\text {auxiliar }}+$ (prep) $+\mathrm{V} 2_{\text {infinitivo }}$ quanto as noções semânticas de movimento e de força, que lhe permitem a conotação cumulativa de duas noções aspectuais: a inceptividade e a continuidade/duração do evento expresso por V2. Isso comprova que os mecanismos da mudança linguística são universais e que, portanto, é possível interpretar o presente à luz do passado.

Os resultados alcançados com este estudo trazem, sem dúvida, contribuições para a descrição da categoria aspectual na língua portuguesa, mas também instauram um dialogismo com perspectivas futuras de análise, na medida em que abrem precedente para investigações diacrônicas mais incisivas, capazes de auxiliar no entendimento da ordenação da categoria TAM, além de incitar novas tentativas de se aplicar os pressupostos da teoria da mesclagem para solucionar questões diacrônicas.

\section{Agradecimentos}

Agradecemos ao Prof. Dr. Johnny José Mafra pela valiosa arguição na banca de Paula (2014), durante a qual nos alertou para a existência do registro gramatical do verbo danar já na língua latina, bem como à Profa. Dra. Heloísa Maria Moraes Moreira Penna pelas pacientes orientações acerca de algumas traduções e de idiossincrasias da gramática latina.

\section{Referências}

BYBEE, J. Morphology: a study of the relation between meaning and form. Amsterdam, Philadelphia: John Benjamins, 1985.

BYBEE, J. Usage-based theory and grammaticalization. In: HEINE, B.; NARROG, H. (Ed.). The Oxford handbook of grammaticalization. New York: Oxford University Press, 2012. p. 7783. Disponível em: <http://www.oxfordhandbooks.com/view/10.1093/ oxfordhb/9780199586783.001.0001/oxfordhb-9780199586783-e-6>. Acesso em: 23 ago. 2016. 
BYBEE, J.; PERKINS, R.; PAGLIUCA, W. The evolution of grammar: tense, aspect, and modality in the languages of the world. Chicago: The University of Chicago Press, 1994.

COELHO, S. M. A gramaticalização das formas verbais (a)garrar, danar, desandar e desatar para expressão das categorias aspectuais incoativa, cursiva e iterativa na língua portuguesa. Revista Virtual de Estudos da Linguagem, [S.1.], v. 12, n. 22, p. 1-24, mar. 2014. Disponível em: <http:// www.revel.inf.br/files/d0af66dd5263e9f207bb40c3db196505.pdf > . Acesso em: 20 jul. 2016.

COELHO, S. M. Estudo diacrônico do processo de expansão gramatical e lexical dos itens ter, haver, ser, estar e ir na língua portuguesa. 2006. $321 \mathrm{f}$. Tese (Doutorado em Estudos Linguísticos) - Faculdade de Letras, Universidade Federal de Minas Gerais, Belo Horizonte, 2006.

COUTINHO, I. de L. Pontos de gramática histórica. 6. ed. rev. Rio de Janeiro: Livraria Acadêmica, 1969.

CUNHA, A. G. da. Dicionário etimológico Nova Fronteira da língua portuguesa. 2. ed. rev. aum. Rio de Janeiro: Nova Fronteira. 1997.

ESTEVES, L. Paredes. Alma de Poeta, [entre 2000 e 2008]. Disponível em: $<\mathrm{http}: / / \mathrm{www}$.almadepoeta.com/lauraestevesprosa.htm $>$. Acesso em: 8 abr. 2010.

FARIA, E. Gramática superior da língua latina. Rio de Janeiro: Livraria Acadêmica, 1958.

FAUCONNIER, G. Mappings in thought and language. Cambridge: Cambridge University Press, 1997.

FAUCONNIER, G.; TURNER, M. Blending as a central process of grammar. Versão expandida. [S.1.]: [s.n.], c1998. Não paginado. Disponível em: <http://markturner.org/centralprocess.WWW/ centralprocess.html >. Acesso em: 17 set. 2016.

GOLDBERG, A. Constructions: a construction grammar approach to argument structure. Chicago: The University of Chicago Press, 1995.

GRECO, A. O São Paulo goleava até dormir no ponto e levar susto do Coritiba. Estadão, 28 jul. 2011. Esporte. Blog. Disponível em: $<$ http:// esportes.estadao.com.br/blogs/antero-greco/o-sao-paulo-goleava-atedormir-no-ponto-e-levar-susto-do-coritiba/>. Acesso em: 28 jul. 2011. 
HARBSMEIER, C. Wilhelm von Humboldts Brief an Abel Rémusat und die philosophische Grammatik des Altchinesischen. Stuttgart: Erich Fromman, 1979. (Grammatica Universalis, 17).

HEINE, B.; CLAUDI, U.; HÜNNEMEYER, F. Grammaticalization: a conceptual framework. Chicago: University of Chicago Press, 1991.

HOPPER, P. On some principles of grammaticalization. In: TRAUGOTT, E. C.; HEINE, B. (Org.). Approaches to grammaticalization. Amsterdam: John Benjamins, 1991. p. 17-35.

KÖVECSES, Z. Metaphor: a practical introduction. 2. ed. New York: Oxford University Press, 2010.

LAKOFF, G.; JOHNSON, M. Metáforas da vida cotidiana. São Paulo: Mercado das Letras, 2002.

LEVERETT, F. P. (Ed.). A new and copious lexicon of the Latin language. Compiled chiefly from the Magnum totius latinitatis lexicon of Facciolati and Forcellini and the German works of Scheller and Luenemamn. ed. fac-sim. London: Richard James Kennett; Boston: John H. Wilkins, 1842. Disponível em: <https://archive.org/ details/1837newcopiousle00leveuoft>. Acesso em: 15 jun. 2016.

MACHADO, J. P. Dicionário etimológico da língua portuguesa: com a mais antiga documentação escrita e conhecida de muitos vocábulos estudados. 4. ed. Lisboa: Livros Horizonte, 1987.

MEU lado ateu e as contradições da Bíblia! Parte 2 - texto de Leiteiro. Over Mundo, 2007. Disponível em: <http://www.overmundo.com.br/ $\mathrm{banco} / \mathrm{meu}$-lado-ateu-e-as-contradicoes-da-biblia-parte-2-texto-deleiteiro>. Acesso em: 9 out. 2007.

NASCENTES, A. Dicionário etimológico da língua portuguesa. Rio de Janeiro: Francisco Alves: Acadêmica, 1933.

PAULA, T. F. de. Estudo do processo de gramaticalização do verbo danar para marcação de aspecto no português brasileiro. $2014.91 \mathrm{f}$. Dissertação (Mestrado em Estudos Linguísticos) - Faculdade de Letras, Universidade Federal de Minas Gerais, Belo Horizonte, 2014.

PAULA, T. F. de; COELHO, S. M. The metaphor in the grammaticalization process of the verb danar to express inceptive aspect with extension of the action in Brazilian Portuguese. Revista Brasileira de Linguística Aplicada, Belo Horizonte, v. 15, p. 453-473, 2015. 
RAVIZZA, J. P. Gramática latina. 9. ed. Niterói: Escolas Profissionais Salesianas, 1940.

SAID ALI, M. Gramática histórica da língua portuguesa. 8. ed. rev. atual. São Paulo: Companhia Melhoramentos; Brasília, DF: Editora Universidade de Brasília, 2001.

TALMY, L. Force dynamics in language and cognition. Cognitive Sciences, Cognitive Science Society, v. 12, n. 1, p. 49-100, 1988.

TALMY, L. Toward a cognitive semantics. Cambridge, MA: The MIT Press, 2000. 2 v.

TENUTA, A. M. Uma breve introdução à teoria dos espaços mentais e da teoria da mesclagem. In: HERMONT, A. B.; ESPÍRITO SANTO, R. S. do; CAVALCANTE, S. M. S. (Org.). Linguagem e cognição: diferentes perspectivas - de cada lugar um outro olhar. Belo Horizonte: PUC-Minas, 2010. p. 85-103.

TOMASELLO, Michael. Constructing a language: a usage-based theory of language acquisition. Cambridge, MA: Harvard University Press, 2003.

TRAVAGLIA, L. C. O aspecto verbal no português: a categoria e sua expressão. Uberlândia: Imprensa Universitária, 1985.

TRAVAGLIA, L. C. Uma gramaticalização em cadeia para indicação de aspecto. In: VITRAL, L.; COELHO, S. (Org.). Estudos de processos de gramaticalização em português: metodologias e aplicações. Campinas, SP: Mercado de Letras, 2010, p. 105-137. 